\title{
LAÇO SOCIAL E ESPETÁCULO MIDIÁTICO NA TECNOCULTURA AO REDOR DO FOGÃO
}

\section{SOCIAL LINK AND MEDIA SPECTACLE IN THE TECHNOCULTURE AROUND THE COOKER}

\section{Carlos Alberto ZANOTTI ${ }^{1}$; Amanda Maria Artioli PEZZO ${ }^{2}$}

Resumo: Este trabalho tem por objetivo debater, a partir da pesquisa bibliográfica e conhecimento empírico, a proliferação e as razões do sucesso alcançado pelos programas de culinária na televisão brasileira - um fenômeno de dimensão praticamente universal. Com atenção especial aos reality shows, aqui são observadas duas dimensões relativas às propriedades da televisão: a construção de laços sociais e a transformação de anônimos em protagonistas de espetáculos, nos quais a audiência encontra várias "posições de sujeito" (KELLNER, 2001) mediadas por uma "coincidência identificatória" (CRAVEIRO, 2004). A hipótese trabalhada é a de que produções televisivas com tais propriedades oferecem elementos para a produção de espetáculos midiáticos consoantes com o estágio do desenvolvimento tecnocapitalista, quando se consolida uma cultura na qual mídia e tecnologia se tornam seus princípios organizadores.

Palavras-chave: Sociedade midiatizada; Culinária na televisão; Reality shows.

Abstract: This study aims to discuss, from the bibliographical research and empirical knowledge, the proliferation and the reasons for the success achieved by cooking shows on brazilian television - a phenomenon of global dimension. With special attention to reality shows in Brazil, two dimensions are related to the properties of television: the construction of social bonds and the transformation of anonymous into protagonists of spectacles in which the audience finds several "positions of subject" (KELLNER, 2001) moderated by an "identification coincidence" (CRAVEIRO, 2004). The hypothesis worked out is that television productions with such properties offer elements for the production of television spectacles in according to the stage of technocapitalist development, consolidating a culture in which media and technology become its organizing principles.

Keywords: Mediatized society; Cooking on television; Reality shows.

\footnotetext{
1 Jornalista, professor e pesquisador da Faculdade de Jornalismo e do Programa de Pós -Graduação Linguagens, Mídia e Arte da PUC-Campinas. Doutor em Ciências da Comunicação pela Escola de Comunicação e Artes (ECA) da Universidade de São Paulo.

2 Professora da Faculdade de Jornalismo da Pontifícia Universidade Católica de Campinas e mestranda pelo Programa de Pós-Graduação em Linguagens, Mídia e Arte, da mesma instituição.
} 


\section{miDiA 醒 DiAno}

\section{Introdução}

Nos últimos anos, a televisão brasileira de sinal aberto foi invadida por programas voltados à culinária, reproduzindo-se aqui um fenômeno de dimensão quase global. Entre os programas que promovem competições e os que se dedicam a ensinar pratos sofisticados ou corriqueiros, doces ou salgados, à beira do fogão ou de churrasqueiras, em canais abertos ou por assinatura, nacionais ou estrangeiros, somamse mais de 50 produções - número que continua aumentando. Desta maneira, com o controle remoto à mão, caso se disponha a tanto, o espectador consegue dedicar todo seu tempo à frente da TV somente procurando receitas e competições em torno do fogão. Aprenderá truques de culinária, rituais alimentares e observará comportamentos em meio a panelas, além de acompanhar diálogos típicos de um ambiente que faz parte da arquitetura de todas as residências - a cozinha, espaço destinado ao atendimento de uma necessidade comum a todos.

A existência de tantos programas às voltas com a preparação de alimentos poderia ser, segundo Craveiro (2004), decorrente de uma "coincidência identificatória" a ligar personagens e audiência neste gênero televisivo, o que explicaria a adesão do público. Afinal, de um jeito ou de outro, todos temos alguma relação com a cozinha, nem que seja para manter uma distância prudente em relação a ela, não sem algum grau de frustração. As produções televisivas de maior audiência em culinária inserem-se no gênero reality show, no qual pessoas desconhecidas se candidatam a vencer um concurso, cumprindo exigências de um corpo de jurados ou os caprichos de um chef famoso. Além da performance na culinária, o próprio desempenho dos concorrentes anônimos na conquista por empatia conclama à identificação sugerida por Craveiro. "Através da realidade representada, os indivíduos identificam-se com os dramas e veem-se nos anônimos" (CRAVEIRO, 2004, p. 29), aponta a autora referindo-se aos participantes da chamada TV de realidade, que buscam reconhecimento e fama, além de um prêmio em dinheiro ou recompensas que envolvem outros ganhos materiais.

O processo de identificação sugerido por Craveiro, no entanto, não estaria circunscrito ao ambiente levado ao ar ou na torcida pelo desempenho dos participantes em se tratando de competições. Em trabalho no qual procurou defender a hipótese de que os alimentos são também dotados de uma "função comunicacional", Rocha (2010) 


\section{eco \\ DiAno}

lembra que comer é, acima de tudo, um ato impregnado de simbolismos. Mais que fornecer nutrientes e satisfazer a uma dimensão instintiva, a comida serve para intensificar trocas culturais e reconfigurar repertórios alimentares e cerimoniais de consumo:

Neste contexto, assim como um elemento-chave para a constituição de identidades, a comida pode ser pensada como um meio de comunicação. [...] além de um meio de transmissão de valores simbólicos e significados diversos, ela é um instrumento comunicativo. É sabido, por exemplo, que é muito mais fácil entrar em contato com a cultura do outro compartilhando o seu alimento, do que falando a sua língua. (ROCHA, 2010, p. 4)

Este caráter particular da gastronomia também foi observado por Tucherman (2010) em trabalho dedicado a explorar a presença da gastronomia no universo midiático contemporâneo. A autora recorre à literatura clássica e moderna, ao cinema, televisão e jornais para explicar a evolução e os diversos sentidos que a alimentação adquiriu na cultura ao longo do processo civilizatório. A autora não deixa de recorrer a uma observação filosófica para lembrar que a gastronomia “[...] desarma o ódio, facilita os negócios e nos oferece, na curta trajetória de vida, o único prazer que não se acompanha de fadiga e ainda nos descansa de todos os outros." (BRILLAT-SAVARIN, 1995, apud TUCHERMAN, 2010, p. 316).

A associação entre meios de comunicação e comida não é recente e nem exclusiva da programação da TV. A novidade foi passar a disputar audiências que até então se entretinham com a teledramaturgia, com programas artísticos e com os telejornalísticos. De pequenos quadros para descontração ou merchandising em programas de variedades, a culinária ganhou protagonismo ao obter, a partir da mistura daqueles três gêneros (dramaturgia, arte e informação), uma receita movida a elementos dramáticos, estéticos e informativos a um só tempo. Com isso, consegue abarcar duas dimensões que tipificam o entretenimento: a construção de laços sociais e a produção do espetáculo - este, um componente inerente à vida social desde os tempos pré-modernos (KELLNER, 2003).

\section{A dimensão do laço social}




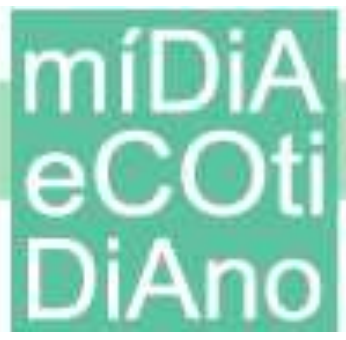

Quando formulou sua hipótese sobre a organização e funcionamento sistêmico da sociedade, Luhmann (2005) avaliou que o sistema midiático possui três distintos ingredientes: jornalismo, publicidade e entretenimento. A nosso ver, no caso dos programas culinários, estes ingredientes estão reunidos em um mesmo gênero televisivo, rompendo linhas divisórias que demarcavam com alguma clareza os limites de uns e de outros. Fazem parte de um gênero contemporâneo ao qual se convencionou chamar de infotenimento (KELLNER, 2003), cujos conteúdos - a cozinha e seus acessórios - são de grande importância para o mercado publicitário, ao mesmo tempo que permitem construir narrativas carregadas de informação e dramaticidade.

Embora as produções que reúnem entretenimento e informação estejam presentes em vários outros suportes, é possivelmente no campo audiovisual que encontram o terreno mais fértil para se desenvolver e se conectar a suas audiências. $\mathrm{Na}$ $\mathrm{TV}$, se transformam em produto de uma etapa civilizatória moldada por uma tecnocultura, na qual "mídia e tecnologia se tornam seus princípios organizadores" (KELLNER, 2001, p. 10). Em obra na qual explorou o tema, Kellner aponta que a televisão contemporânea assume algumas das funções tradicionalmente atribuídas ao mito e ao ritual. Em outros termos, integra indivíduos em uma determinada ordem social, "celebrando valores dominantes, oferecendo modelos de pensamento, comportamento e sexo para imitação, etc" (KELLNER, 2001, p. 304).

Casetti e Odin (2012) partem do princípio de que a televisão atua enquanto instituição que faz uso de "contratos de comunicação" com os objetivos de transmitir saberes de forma direcionada e dirigida, fundada na separação claramente hierarquizada dos papéis desempenhados por produtores e públicos. Ao longo de sua trajetória, a televisão apresenta, ao menos em termos semiopragmáticos, duas distintas etapas de desenvolvimento, caracterizadas como paleo e neotelevisão. A paleo se caracteriza por apresentar ao público uma grade pedagogicamente organizada, coerente, "de nós para eles", demarcada por valores hierárquicos inerentes à própria origem deste suporte midiático. Já na neotelevisão, a grade de programação é menos orgânica, sujeita a interatividade e ambientada num "espaço de convívio" (CASETTI; ODIN, 2012, p. 11) ao qual o espectador é chamado a participar. 
Este espaço de convívio atinge o ponto máximo ao associar-se à coincidência identificatória de que fala Craveiro. De um modo geral, o fogão, as receitas e o manejo dos alimentos são familiares demais para produzir exclusões significativas. E neste processo de não exclusão, estes elementos reúnem importantes potenciais para promover uma intensa socialização, como pondera Kellner:

[...] a cultura da mídia põe à disposição imagens e figuras com as quais seu público pode identificar-se, imitando-as. Portanto, ela exerce importantes efeitos socializantes e culturais por meio de seus modelos de papéis, sexo e por meio de várias "posições de sujeito" que valorizam certas formas de comportamento e modo de ser enquanto desvalorizam e denigrem outros tipos. (KELLNER, 2001, p. 307)

A noção da televisão enquanto formadora de laços sociais também aparece em Dominique Wolton (1996), sociólogo francês que construiu um de seus principais argumentos a favor da TV geralista quando pesquisou este veículo exatamente no Brasil. Em um de seus trabalhos mais importantes, o autor defende a tese de que a TV aberta é um meio mais democrático de comunicação quando comparada às emissoras por assinatura. Sua condição democrática estaria diretamente associada à percepção dos índices de audiência, indicador que baliza os conteúdos da grade de programação.

Qual é o caráter da televisão? Reunir indivíduos e públicos que tudo tende a separar e oferecer-lhes a possibilidade de participar individualmente de uma atividade coletiva. É a aliança bem particular entre o indivíduo e a comunidade que faz desta técnica uma atividade constitutiva da sociedade contemporânea. (WOLTON, 1996, p.15).

Quando investiga a noção de laço social, o pensador francês recorre à origem do conceito do termo, que se localiza a partir de Durkheim e da escola francesa de sociologia, em uma perspectiva inicialmente mais voltada à vida institucional. E aponta que, posteriormente, o conceito teria sido estendido a dimensões como trabalho, educação ou saúde, mas ainda sob o viés institucional. Wolton desloca o conceito para aspectos menos institucionalizados da vida, dos quais a televisão seria um dos principais artífices. Tem-se então que, de um modo geral, a TV construiria laços sociais à medida que o espectador, ao sentar-se frente ao aparelho, agrega-se a um público potencialmente imenso e anônimo, com os quais estabelece uma espécie de ligação invisível. Para o autor, há dois sentidos de laço nessa relação. O primeiro, de caráter especular e silencioso, nos remetendo à ideia de um espelhamento de si, como podemos 
observar na obra de Khel (2004). E o segundo, quando a TV apresenta um espelho no qual a sociedade é quem oferece a representação de si. "E ao fazer a sociedade refletirse, a televisão cria não apenas uma imagem e uma representação, mas oferece um laço a todos aqueles que a assistem simultaneamente" (WOLTON, 1996, p.124).

\section{A dimensão do espetáculo}

Em trabalho no qual investiga, sob a ótica da teoria crítica e dos estudos classificados de pós-modernos, a razão da proliferação de reality shows nas emissoras portuguesas, Craveiro (2004, p.15) observa que o fato se deve grandemente à concorrência que a televisão tem encontrado por parte das mídias que surgiram com os novos meios de comunicação ${ }^{3}$. Já não é preciso sintonizar um canal de TV para ver um programa de informação ou de entretenimento. Eles estão disponíveis no grande banco de dados da rede mundial de computadores, simultaneamente, em todos os idiomas, com os mais variados formatos ou narrativas, incluindo as tradicionais produções levadas diariamente ao ar. Para enfrentar esta ameaça ao seu poderio, a televisão tem repensado sua programação e, consequentemente, destinado mais espaço aos programas de entretenimento, se comparado aos de informação. Ou mesmo transformado a informação em entretenimento:

$\mathrm{Na}$ lógica de funcionamento deste médium, a estética realista assume como função prioritária o entretenimento: o recurso a elementos simbólicos facilmente reconhecíveis (em geral extraídos diretamente da própria "realidade") e a gêneros familiares (a narrativa, por excelência) como fórmula de máxima eficácia para "conquistar" audiências (a captação de atenção dos destinatários e a orientação em conformidade com seus interesses). (CRAVEIRO, 2004, p. 21)

A autora recorre à obra de Traquina (1997, p.13) para observar que a televisão contemporânea tem apresentado uma "maior tendência para a escolha de formatos que exigem as condições narrativas inerentes ao espetáculo, assim como para a escolha de temas que implicam uma certa personalização e jogam com a intensidade das emoções".

3 Levantamento da empresa francesa de consultoria Zenith aponta que, no ano de 2016, em termos globais, a internet já havia ultrapassado a televisão enquanto veículo preferencial para investimentos publicitários. Ver: GOOGLE e Facebook têm $20 \%$ da publicidade global, diz consultoria. Folha de S. Paulo, Mercado, A20, 04 Mai 2016. 
É o que se observa nos realities culinários, que apresentam ingredientes da primeira e segunda fases da televisão mencionadas anteriormente. Da primeira fase, compreendese a produção de um espetáculo feito "de nós para eles". Da segunda, destaca-se a busca por novos protagonistas a partir da própria audiência, do cidadão comum e anônimo chamado a participar da programação. A propósito do tema, Rocha (2010) destaca que os realities dos quais participam os telespectadores são potencialmente menos onerosos que os programas de entretenimento tradicionais, onde atuam artistas famosos com cenografia mais arrojada.

Desta forma, observa-se que os realities culinários apresentam uma mistura dos gêneros que Luhmann separava com alguma clareza, todos em benefício da criação de um espetáculo atraente, crível e rentável. $\mathrm{Na}$ narrativa de um mesmo episódio, a exemplo das franquias do MasterChef, reúnem-se informação jornalística (quando elabora perfis, recolhe depoimentos e apresenta localidades); entretenimento (quando conduz histórias recobertas de suspense, trilha sonora e edição privilegiando a tensão da disputa); e propaganda (quando divulga marcas e produtos dos patrocinadores). Programas desta natureza são considerados um subgênero da TV de realidade, cuja principal estratégia de sedução é espetacularizar o cotidiano:

A característica da televisão de realidade está no conteúdo, feito por pessoas comuns, fatos reais, depoimentos individuais. Um reality show que trata de questões de familia traz depoimentos pessoais, problemas do cotidiano, pessoas que sofrem expondo sua experiência. Um programa que trata de reconstituição de crimes faz a reconstituição de problemas individuais e permite que pessoas comuns se expressem no espaço televisivo. Existe, portanto, uma característica comum, mas existem diversos subgêneros desse gênero maior que é o show de "realidade", seja ela cotidiana ou produzida. (GARCIA; VIEIRA; PIRES, 2006, p. 6)

Vinte anos atrás, Kellner já observava que o alimento caminhava para ingressar no circuito do espetáculo da sociedade que denominou de tecnocapitalista derivada da associação entre capitalismo, tecnologia e indústria da informação e do entretenimento. Em Media spectacle, o autor relaciona diversos longas-metragens hollywoodianos, revistas e best-sellers do mercado editorial que estariam apresentando a comida "com os excessos pornográficos geralmente reservados ao sexo" (KELLNER, 2003, p. 9). A associação de culinária e televisão - mídia que oferece modelos para 


\section{miDiA \\ ecot \\ DiAno}

pensar e se comportar - permite narrativas que incorporam os principais ingredientes de um espetáculo: jogam com emoções, sentimentos e expectativas. Testemunham-se vitórias e fracassos, risos e lágrimas, beleza e fealdade, amizade e ressentimentos. Esse caldeirão de emoções vivenciadas nas locações, e potencializadas pela edição, é servido à teleaudiência que, nestes programas, encontra um conjunto de "posições de sujeito" que vão se revelando: "Eu gosto da Bruna, mas eu amo o Léo"4, desculpou-se aflita uma telespectadora, através do Twitter, durante episódio final do MasterChef Brasil 2016.

\section{Teleculinária no Brasil}

A culinária chegou à televisão brasileira pelas mãos da apresentadora Ofélia Ramos Anunciato, que estreou um programa feminino na antiga TV Tupi em 1958, tendo posteriormente se transferido para a TV Bandeirantes, onde durante 30 anos comandou A Cozinha Maravilhosa de Ofélia. Descrita como "a grande dama da cozinha brasileira" em editorial da Revista Gula (DEMOZZI, 2014), Ofélia dava um caráter didático à produção, ensinando leigos a cozinhar - a mesma característica que implementou nos 11 livros que escreveu e nas mais de 20 mil receitas que ensinou. Hoje, uma boa parte dos programas de culinária na televisão aberta já não se destina exclusivamente ao público feminino, mas continua oferecendo um bom pretexto para conversar e envolver o telespectador.

Uma parte destes programas está voltada à competição, modalidade que chegou à TV aberta brasileira em 8 de setembro de 2008, através do programa Mais Você, apresentado por Ana Maria Braga e veiculado na Rede Globo. O quadro levou o nome de Super Chef, no qual os participantes permaneciam em semiconfinamento, assistiam a aulas com chefs renomados da gastronomia e competiam entre si na produção de receitas que exigiam conhecimento técnico e criatividade. Até o ano de 2016, foram exibidas oito edições do Super Chef, sendo que as três primeiras tiveram a participação de cozinheiros amadores e, nas cinco seguintes (Super Chef Celebridades), os competidores eram atores, cantores e atletas conhecidos do público.

4 Mensagem encaminhada por twitter@kallinesakurada. Ver: MASTERCHEF BRASIL, 2016. Parte 1 Leonardo e Bruna chegam para a grande final do MasterChef Brasil. Rede Bandeirantes de Televisão 


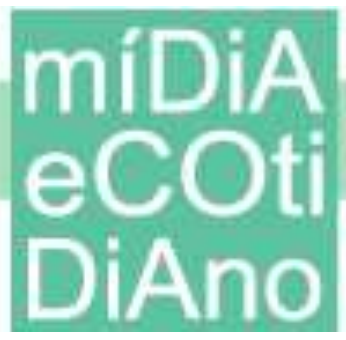

Na Globo, este formato de quadro ganhou reforço no ano de 2012, quando o Mais Você passou a contar com o quadro Jogo de Panelas. Uma vez mais, os concorrentes eram pessoas desconhecidas do público e tinham em comum o hobby de ir para a cozinha de vez em quando. Em 2014, quadros semelhantes foram adotados por outras emissoras, dando origem a programas exclusivos, independentes, que foram compor grades de programação principalmente no horário noturno. A primeira emissora aberta a explorar este mercado foi a rede Bandeirantes, com o programa MasterChef Brasil, cuja estreia ocorreu em setembro daquele ano. Pelo formato da franquia, os participantes, cozinheiros amadores, passam por uma pré-seleção acompanhada pelo público até que se forme o grupo oficial que reúne entre 14 e 20 integrantes. $\mathrm{Na}$ produção, quem avalia o desempenho dos participantes é um corpo de jurados composto por três chefs de gastronomia. Os competidores, por sua vez, são colocados em provas semanais, avaliados e classificados para as etapas seguintes, ou são eliminados. O vencedor, como nos demais programas do formato, ganha prêmio em dinheiro, além de um curso de gastronomia e brindes oferecidos pelos patrocinadores. O programa já está sem sua sexta edição na emissora, sendo que uma delas levou o nome MasterChef Junior, na qual crianças concorreram entre si. Recente no Brasil, o formato teve origem no Reino Unido, em 1990. Atualmente, é exibido em mais de 40 países.

Um mês após a estreia do MasterChef Brasil, o SBT lançou o programa Cozinha Sob Pressão, em outubro de 2014. Pelo formato, os competidores são divididos em duas equipes para participar da disputa $\mathrm{e}$, ao final da temporada, quando restam 5 participantes, a competição segue individualizada e o prêmio para o vencedor é pago em barras de ouro. Em cada episódio, o desafio é sempre servir um jantar, sendo eliminado em cada episódio aquele que apresentar o pior desempenho. A origem deste programa é também britânica, já tendo havido quatro edições brasileiras. Da terceira em diante, assumiu o nome original de Hell's Kitchen.

Em julho de 2015, o SBT estreou o Mão na Massa, outro reality culinário, exibido nas noites de sábado. O programa é mais específico que o anterior em relação ao talento dos participantes, uma vez que são desafiados a executar receitas de confeitaria, como bolos, tortas e pães, entre outras variedades de doces e salgados. O desempenho dos competidores é avaliado por uma confeiteira profissional e um 
empresário do setor, aos quais é atribuída a missão de escolher quem será o eliminado ao final de cada episódio. Este formato é também importado da Inglaterra, estando presente em outros 20 países com o nome The Great Bake Off. No Brasil, por enquanto, teve apenas uma temporada.

Seguindo nesta mesma concepção, a Rede Record também inseriu na grade da emissora, em setembro de 2015, o programa Batalha dos Confeiteiros. Exibido nas noites de quarta-feira, foi comandado pelo apresentador, chef e empresário americano Buddy Valastro. O vencedor do torneio recebeu como prêmio o cargo de administrador da primeira filial brasileira da Carlo's Bakery - padaria que Valastro montou em Nova Jersey (EUA). O estabelecimento é utilizado como principal cenário do programa Cake Boss, apresentado nos canais pagos TLC e Discovery Home \& Health, onde é possível acompanhar o dia a dia da família Valastro na gestão negócio, com especial atenção aos bolos esculturais ali preparados.

Em fevereiro de 2016, o SBT investiu em mais um reality disputado em torno do fogão. Desta vez, os competidores, todos amadores na cozinha, tiveram que dar conta das técnicas de preparação de carnes no programa $B B Q$ Brasil - Churrasco na Brasa. Eles participaram de provas individuais e em grupo, procurando saciar o apetite de grandes públicos. Também foram avaliados por jurados técnicos e disputaram prêmios como produtos oferecidos pelos patrocinadores e o troféu do programa. Exibido nas noites de sábado, o BBQ reveza-se com a veiculação do Cozinha Sob Pressão.

À exceção dos dois precursores do formato veiculados no período matutino, as produções mais recentes ganharam status de horário nobre das emissoras de televisão, compreendido entre $19 \mathrm{~h}$ e $22 \mathrm{~h}$. A estratégia indica que, como o formato dos programas de culinária mudou, o público também se alterou. Enquanto a programação matutina é voltada para as mulheres, a noturna tende a atingir toda a família.

Em pesquisa realizada nos EUA, onde os diversos reality shows culinários surgiram em 2001, Ebersole e Woods (2007) procuraram conhecer as motivações para a audiência desses programas. Entre os fatores, encontraram dois que se sobressaíram: a identificação com personagens reais e a participação vicária que tais produções propiciam. Nos dois casos, trata-se de fazer com que o público sinta-se representado nos jogos propostos, cujo resultado final não se conhece previamente, diferentemente do 


\section{ecot DiAno}

que ocorre com as produções artísticas convencionais. Tais produções responderiam a demandas da etapa de desenvolvimento econômico que se caracteriza por um "capitalismo artista", quando a atividade produtiva "cria em grande escala o sonho, o imaginário, as emoções" (LIPOVETSKI; SERROY, 2015, p. 27).

Não foi sem razão, portanto, que o episódio final da versão 2016 do MasterChef Brasil, na Rede Bandeirantes, recebeu mais de 1 milhão de tuítes de seus espectadores. Apresentado pela jornalista Ana Paula Padrão, o programa foi apoteoticamente ao ar, com direito a trilha sonora e acordes épicos, tapete vermelho para a chegada dos competidores finais e traje de gala para os jurados. Afinal, como garantia a apresentadora, o vencedor levaria "o troféu que vai abrir as portas para vocês no mundo da gastronomia" (MASTERCHEF BRASIL, 2016). Curioso foi observar que os jurados Henrique Fogaça, Paola Corosella e Erik Jacquin - que conseguiram obter grande empatia com o público - decoraram muito bem os tempos verbais para se referir, ao vivo, a uma competição de cuja gravação já haviam participado.

Enquanto apresentava os protagonistas e holofotes movimentavam luzes pelo palco, a ex-jornalista da Rede Globo sustentava aos espectadores que, além de terem crescido como cozinheiros, os finalistas cresceram "também como estrategistas" - uma clara alusão às identificações que conquistaram junto ao público e às bem sucedidas articulações internas. Minutos antes, um automóvel recém-lançado por uma grande montadora havia transportado os finalistas até a emissora, onde um "estúdio interativo" patrocinado por uma empresa de telefonia celular cuidava das repercussões nas redes sociais. Nas imagens da disputa na cozinha, um grande volume de alimentos industrializados ostentava o nome da rede de supermercados que patrocinou a edição do programa. Todos com direito a marcas e logotipos em primeiro plano, o que explicita parte do modelo de negócios formulado para a franquia.

\section{Considerações finais}

O sucesso alcançado por reality shows culinários, em diferentes países do globo, reafirma o avanço televisivo do infotenimento na linha de programas que espetacularizam algumas dimensões particulares da vida cotidiana. É o caso da arte de cozinhar, que agrega a agilidade em torno do fogão no preparo do alimento - este, por si 


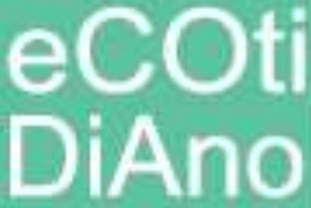

só, um "ator" que, no cenário midiático, deixou de atuar nos intervalos para conquistar a condição de protagonista no horário nobre. Potencialmente, programas desta natureza oferecem inúmeras oportunidades para o advento de posições de sujeito a serem experimentadas pela audiência em um ambiente de identificação comum a todos os lares. Interessantemente, junto com a receita que lhe confere os principais ingredientes da espetacularização, a proposta traz também uma modelagem de negócio que a TV aberta experimenta para o enfrentamento que, nos próximos anos, fará com as novas mídias que surgirão na esteira do desenvolvimento da internet.

\section{Referências}

BRILLAT-SAVARIN, Antoine. A fisiologia do gosto. São Paulo: Companhia das Letras, 1995.

CASETTTI, Francesco; ODIN, Roger. Da paleo à neotelevisão: abordagem semiopragmática. Ciberlegenda, Niterói (ri), n. 27, p.8-22, 2012. Disponível em: <http://www.ciberlegenda.uff.br/index.php/revista/article/view/596/339>. Acesso em: 2 fev. 2016.

CRAVEIRO, Sofia. Reality shows - o espetáculo das massas. Agoranet, Covilhã, v. 4, p.1-40, 2004. Disponível em: <http://labcom-ifp.ubi.pt/files/agoranet/04/craveiro-sofiateoria-critica-industria-cultural.pdf>. Acesso em: 4 dez. 2016.

DEMOZZI, Sabrina Fernanda. A cozinha em pauta: história, identificação e sentimento nas práticas da cozinha do cotidiano e na cozinha como lazer. 2014. $149 \mathrm{f}$. Dissertação (Mestrado) - Curso de História, Ciências Humanas, Universidade Federal do Paraná, Curitiba (PR), 2014.

EBERSOLE, Samuel; WOODS, Robert. Motivations for eviewing reality television: a use and gratifications analysis. Southwestern Mass Communication Journal. Sep. 2007, v. 23 Issue 1, p. 23-42. Disponível em: http://www.uky.edu/ drlane/methods/apa/29994743.pdf $>$. Acesso em: 20 abr. 2016.

GARCIA, Deomara Cristina Damasceno; VIEIRA, Antoniella Santos; PIRES, Cristiane Carneiro. A explosão do fenômeno: reality show. Biblioteca Online de Ciências da Comunicação, Covilhã, 2006. Disponível em: <http://www.bocc.ubi.pt/pag/garciadeomara-reality-show.pdf>. Acesso em: 3 fev. 2017.

GOOGLE e Facebook têm $20 \%$ da publicidade global, diz consultoria. Folha de S. Paulo, Mercado, p. A20, 04 mai. 2016. 
KELLNER, Douglas. A cultura da mídia: estudos culturais: identidade e política entre o moderno e o pós-moderno. Trad. Ivone Castilho Benedetti. Bauru (SP): Edusc, 2001.

Media spectacle. California (USA), Routledge, 2003.

KHEL, Maria Rita. Visibilidade e espetáculo. In: BUCCI, Eugênio; KEHL, Maria Rita. Videologias: ensaios sobre a televisão. São Paulo: Boitempo, 2004.

LIPOVETSKY, Giles; SERROY, Jean. A estetização do mundo: viver na era do capitalis mo artista. Trad. Eduardo Brandão. São Paulo: Companhia das Letras, 2015.

LUHMANN, Niklás. A realidade dos meios de comunicação. São Paulo: Paulus, 2005

MASTERCHEF BRASIL, 2016. Parte 1 - Leonardo e Bruna chegam para a grande final do MasterChef Brasil. Rede Bandeirantes de Televisão. Disponível em: $<$ http $/ /$ entretenimento.band.uol.com.br/masterchef/2016/videos/ultimos-

videos/15969614/parte-1---leonardo-e-bruna-chegam-para-a-grande-final-domasterchef-brasil.html>. Acesso em: 12 fev. 2017.

ROCHA, Carla Pires Vieira. Comida, Identidade e Comunicação: a comida como eixo estruturador de identidades e meio de comunicação. Biblioteca Online de Ciências da Comunicação. Covilhã, 2010. Disponível em: <http //www.bocc.ubi.pt/pag/rochacarla-comida-identidade-e-comunicacao.pdf $>$. Acesso em: 11 jan. 2017.

TRAQUINA, Nelson. Big show media. Lisboa: Notícias Editorial, 1997.

TUCHERMAN, Ieda. Gastronomia, Cultura e Mídia: o longo percurso "Você é o que você come". Revista Famecos. Porto Alegre, v. 17, n. 3, p. 314-323, setembro/dezembro, 2010.

WOLTON, Dominique. O elogio do grande público: uma teoria crítica da televisão. São Paulo: Ática, 1996. 